\title{
O QUE É PERFORMANCE? \\ ENTRE CONTEXTO HISTÓRICO E DESIGNATIVOS DO TERMO
}

\author{
Natalie Mireya Mansur Ramirez \\ UFES-SC
}

\section{Resumo}

Este artigo pretende explorar questões relacionadas aos designativos do termo performance, levando em consideração a abrangência de campos do conhecimento que esta envolve através de autores nacionais e internacionais, bemcomo alguns exemplos históricos. $O$ intuito desta pesquisa não é traçar uma historiografia sobre a arte da performance, mas descrever alguns dados que ajudem na compreensão daquilo que buscamos entender como tal.

\section{Palavras-chave:}

performance, designativos, contexto.

A performance como movimento artístico e autônomo ganha força durante os anos 1970. Na prática performática o artista utiliza seu corpo como suporte, atitude política contra o objeto-produto de arte instituído e precificado. A Arte Conceitual, em voga na época, reiterou o sentido da prática performática ao propor uma arte não material, na qual a ideia atribuída à criação fosse sobressalente a qualquer intenção mercadológica, como reitera a autora Lucy Lippard: "Para mí, el arte conceptual significa una obra em la que la idea tiene suma importância y la forma material es secundaria, de poca entidade, efimera, barata, sin pretensiones $y / 0$ desmaterializada." (LIPPARD, 2004, p.9). A autora ressalta massiva inserção de artistas mulheres no circuito na década de 1970, alegando que os meios de execução como vídeo, performance, fotografia, poemas, textos, livros de artistas, facilitou o acesso e a participação das mesmas, possibilitando que as artistas daquele período pudessem, através do registro, inserirem-se na história da arte. Grande parte da discussão travada por essas artistas se debruçou em questionamentos acerca do papel social da mulher, sua aparência, beleza, autobiografia político-feminista através do uso do próprio corpo.

\section{Abstract}

This article aims to explore some of the performance term assignments considerating fields of knowledge that this term involves, through the discussion from national and international authors and through some historical exemples. The purpose of this research is not to write a historiography of performance art, but to describe some exemples that help in the undertanding about what we think as performance.

Keywords:

performance, assignments, context.

Desde sua "pré-história", termo utilizado pelo o autor argentino Jorge Glusberg para aludir as manifestações performáticas nas vanguardas europeias, muitos outros termos foram utilizados para se referir a performance e entre eles estão Performance Art ou Arte da Performance, Body Art, Happening, Live Art e Lectures. Com tantos designativos é confuso traçar a diferenciação de cada um em relação à performance, mas o que importa salientar é que todos eles estão decodificados dentro do campo da experimentação artística.

No livro intitulado A Arte da Performance, de Jorge Glusberg, o autor afirma que Body Art foi um termo cunhado para tratar de toda manifestação artística que abarcasse a utilização do corpo como veículo de expressão, assim como alega a pesquisadora canadense Amy Dempsey que "A body art é aquela que usa o corpo, geralmente o próprio corpo do artista como um meio. Desde o fim da década de 60 foi uma das mais populares e controvertidas formas de arte e disseminou-se pelo mundo." (DEMPSEY, 2003, p.244). Este guia enciclopédico, da autora citada, denominado de Estilos, Escolas 
e Movimentos, é como um dicionário artístico, pelo qual se busca o movimento estilístico e, por consequência, obtém-se sua contextualização histórica. 0 curioso é que neste guia enciclopédico o termo Arte Performática, outro designativo de Arte da Performance ou Performance Art, está compreendido entre o período de 1945 - 1965, enquanto Body Art se encaixa no período de 1965 até os dias de hoje. Essa observação é pertinente, pois se trouxermos uma das passagens em que Jorge Glusberg analisa a Body Art, a impressão que temos é que a Body Art abriu caminhos para a Arte da Performance, e não o oposto, quando da referência a artistas como Vito Aconcci, Daniel Buren e Gina Pane:

O denominador comum de todas essas propostas era o de fetichizar o corpo humano - eliminando toda exaltação à beleza a que ele foi elevado durante séculos pela literatura, pintura e escultura - para trazê-lo a sua verdadeira função: a de instrumento do homem, do qual por sua vez, depende o homem. Em outras palavras, a body art se constitui numa atividade cujo objeto é aquele que geralmente usamos como instrumento. (...) Ao mesmo tempo, a body art se diluía dentro de um gênero mais amplo - a performance. Enquanto a body art se expandia pela América, Europa e Japão, outros pesquisadores interessados em pesquisar novos modos de comunicação e significação convergem para uma prática que, apesar de utilizar o corpo como matériaprima, não se reduz somente à exploração de suas capacidades, incorporando também outros aspectos, tanto individuais como sociais, vinculados com o princípio básico de transformar o artista em sua própria obra, ou, melhor ainda, em sujeito e objeto de sua arte. (GLUSBERG, 2007, p.43).

O Happening, manifestação artística que tem como expoente significativo o americano Allan Kaprow, influente do grupo intermidiático FLUXUS, geralmente é ligado à ideia de improvisação simultaneamente à participação do público. "A tradução literal de happening é acontecimento, ocorrência, evento. Aplica-se essa designação a um espectro de manifestações que incluem várias mídias, como artes plásticas, teatro, art-collage, música, dança etc." (COHEN, 2002, p.46). Essa definição se aplica também a performance, visto que não foi mencionado o caráter eventual do happening, o que é recorrente quando se trata da intenção de diferenciar o happening da performance. Muitos happenings possuem essa característica, a citar o evento do Grupo Rex , de São Paulo e atuante na década de 1960, com sua Exposição-NãoExposição, um happening de encerramento de sua atividade no qual o público tinha liberdade de fazer o que bem entendesse com as obras ali expostas, tendo a exposição durada apenas 8 minutos, pois acabou na total destruição daquilo que estava dentro da sede do grupo.

Se a diferenciação entre performance e happening se dá pelo caráter de eventualidade, tal diferença só é possível através do conhecimento do quanto há de fortuito neste ou naquele. É muito arriscado diferenciar os dois termos práticos por esse viés, apesar de ser o mais aceito, visto que no embate que a performance traz entre corpo, tempo, espaço e público, que por vezes não é um público convidado, ou seja, o qual não se conhece, a eventualidade está presente. Portanto, talvez o que difira o happening seja o caráter participativo dado ao público, o que faz com que a eventualidade faça parte da proposta. E se pensarmos que tal eventualidade é programada, essa tentativa de diferenciação é invalidada, pois por vezes é atribuído a performance a noção de delineação de um enredo, ou seja, atividade na qual se tem um mínimo de controle sobre o seu desenvolvimento. Se pensarmos ainda que a performance pode ser participativa, ou seja, que ela pode trazer um público para interagir e que isso implica riscos, talvez a diferenciação entre a prática do happening e a performance esteja na frequência da participação do público.

Para comprovar a ideia de improviso ligada ao happening, um dos mais conhecidos e realizados por Alan Kaprow, 18 Happenings in 6 parts, (Figura 01 e 02), de 1959, na Reuben Gallery, NY, foi ensaiado com bastante antecedência. E como tentativa de discernir a prática com seus alunos do California Institut Of Art, Alan Kaprow fazia experimentações denominadas por ele de Activities ou Atividades. De acordo com a pesquisadora brasileira Thaise Nardim, a diferença entre os Happenings e as Activities está na falta da necessidade de compartilhamento da ação com uma audiência imprescindível à sua execução e também pelas Activities constituírem roteiros elaborados, os quais os alunos seguiam, como exemplo (KELLEY apud NARDIM, 2004):

$$
\begin{gathered}
\text { (leito de rio seco) } \\
\text { Molhando uma pedra } \\
\text { Carregando-a rio abaixo até que esteja seca } \\
\text { Largando-a } \\
\text { Escolhendo, escolhendo, lá, outra pedra } \\
\text { Molhando-a } \\
\text { Carregando rio acima até secar. } \\
\text { Largando-a. }
\end{gathered}
$$



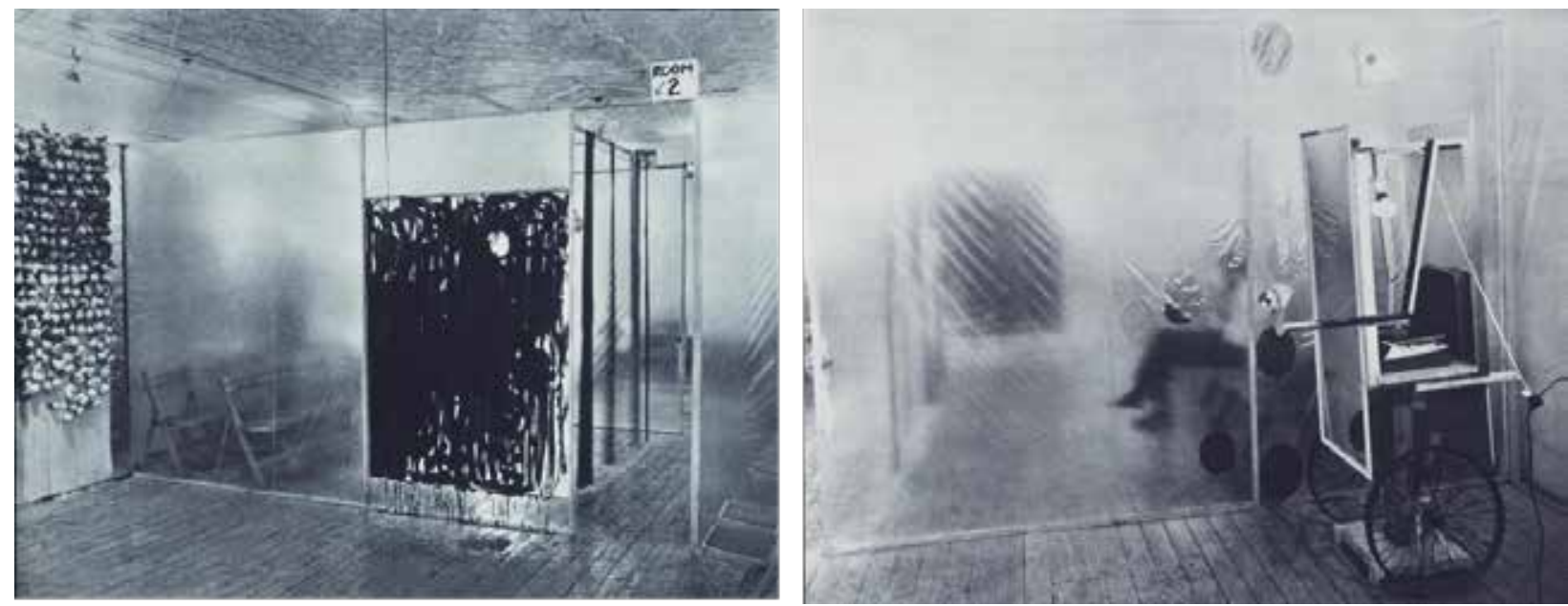

Figura 1 e 2 - Allan Kaprow, 18 Happenings in 6 Parts (1959), Ruben Gallery, New York. Fonte: https://cyberurchin.com

As Activities também surgem como uma resposta à crítica institucional que visava traçar nomenclaturas para os trabalhos de arte inovadores da época, como os happenings, e nessa tentativa de não adequação de seu trabalho com as nomenclaturas do mercado de arte, o artista denomina suas próximas realizações de Activities, aproximando tais a ideia de arte e não arte. Assim como Nardim, Glusberg aponta que o diferencial do Happenning para as Activities também está na ausência de uma plateia, pois Kaprow funde a figura do ator com espectador. Porém, ao analisarmos o Happening e as Activities, mais encontramos semelhanças do que diferenças entre elas para que seja necessária a criação de um segundo termo a fim de se referir a tais ações, pois em ambas as ações Kaprow coordena, através de um pequeno texto, um direcionamento, para que a ação aconteça dentro das possibilidades do imprevisto por ele. Talvez a marca das Activities resida no fato de que eram experimentações com alunos, e nada mais, o que não era uma premissa nos denominados Happennings.

Live Art é outro termo aplicado para designar as artes performativas, porém para a autora americana RoseLee Goldberg, ele faz jus à interdisciplinaridade utilizada por parte dos artistas para criarem seus experimentos corporais, e por isso é preferível utilizá-lo para nos referirmos a arte da performance quando ligada à música, teatro, dança, cinema ou artes visuais. Live Art ou arte ao vivo pode ser entendida como um designativo para qualquer manifestação, no âmbito artístico, em que o artista utilize do seu próprio corpo para produção de sentido: o corpo como suporte, a mensagem como obra, numa tentativa de aproximar arte e vida. 0 termo também está ligado a uma não representação, no sentido mimético-teatral.

O pesquisador brasileiro Renato Cohen afirma que a performance é intimamente ligada as artes cênicas, mas que a mesma rompe com os padrões aristotélicos de representação, narrativa e linearidade. Assim como a performance existem outras manifestações que visam romper com a ideia tradicional de teatro, como o Teatro da Crueldade do dramaturgo francês Antonin Artaud. Deste ponto de vista, o termo Live Art pode ser utilizado para qualquer âmbito artístico, desde que tal manifestação utilize o corpo como motor da obra e a desconstrução de paradigmas como índice, tendo suas origens nos finais dos anos 1990 e para a cofundadora do Live Art Development Agency, Lois Keidan "Live Art não deveria ser entendida como a descrição de uma forma de arte, mas sim, como uma estratégia de inclusão de uma diversidade de práticas e artistas que, em outras circunstâncias, se encontrariam "excluídos" de todos os tipos de política e de apoio e de toda espécie de trabalho de curadoria ou de debate crítico." Porém, já que o termo não se refere a ações específicas e sim com aspectos gerais ao que concerne à arte da performance, podemos dizer que Live Art e Body Art referenciam as mesmas questões: o corpo presente e o tempo real e cronológico em oposição ao tempo experimentado internamente. Não que o artista utilize apenas seu corpo em uma dada ação, mas o importante é frisar que seu corpo é o motor da obra, o fundamental, o suporte, o próprio canvas. 
Nos anos 70, o termo Lectures, ou Leituras, era muito utilizado para se referir a ações performáticas, visto que muitos artistas que faziam performance faziam também publicações de artistas. A recorrência deste termo é encontrada nos arquivos da Fundação Franklin Furnace, fundada por Martha Wilson, em 1976. Muitos artistas que trabalhavam com arte efêmera produziam publicações de artistas, isto é, eles criavam algum tipo de registro impresso ou à escrita que tinham a ver com seus trabalhos, como uma extensão dos mesmos, servindo de apoio ao trabalho. 0 acervo de publicações de artistas do Franklin Furnace se tornou o maior dos EUA, e em 1993 o MoMa o adquiriu, denotando a importância de tal iniciativa. As publicações de artistas funcionavam como um display alternativo para a divulgação do trabalho ou como seu suporte, visto que na época da fundação as instituições desconsideravam a relevância de artes efêmeras, como instalações, publicações e performances. A ideia de Lectures, partindo dos eventos da Franklin Furnace, consistia em apresentações com esses artistas que produziam publicações e performances a ler tais materiais impressos pertencentes ao acervo em algum evento promovido pela fundação. "Desse modo, a página impressa estava sendo considerada não apenas um espaço alternativo, mas era possível entender como as performances (Leituras) davam forma corporal àquelas ideias impressas, expandindo assim a própria noção de publicação." (BORBA; MELIM, 2014, p.85).

Lectures se mostra como um termo que visou especificar uma manifestação performática em um dado micro - contexto (específico), isto é, não se tratava da produção de performance como um todo, nos anos 1960, nos EUA, mas uma parte desse todo, uma parcela de tal produção, na qual a performance consistia na leitura de arquivos pessoais, portfólios, textos de artistas, os quais incorporados ao serem verbalizados pelos próprios autores, eram denominados de Lectures. Se compararmos com os termos designativos que vimos até aqui, podemos perceber que a distinção de Lectures para Performance se dá devido à um padrão na forma de apresentação: texto - artista - corpo presente leitura verbal. Porém, uma nova contradição vem à tona com essa afirmação, pois nos Happenings e Activities, por exemplo, também há um padrão na forma de apresentação.
A pesquisadora brasileira em artes cênicas Beth Lopes afirma que o campo de estudos sobre performance no Brasil ainda está muito ligado as artes visuais, o que nos faz pensar que o termo pode abranger outros campos do conhecimento. Beth Lopes é encenadora e professora brasileira de teatro. Sua pesquisa teórico-prática nesse campo de atuação analisa o conceito de memória como elemento potencial para que um performer estabeleça ou desconstrua laços de identidades coletiva ou individual na criação de uma performance, visto que quando ela utiliza o termo performer em vez de ator ela se refere "aquele que não se restringe à interpretação teatral no sentido convencional, mas transita por diferentes campos do conhecimento, desfronteriza as linguagens, amplia as noções espaciotemporais e fricciona as relações entre o real e o ficcional incorporando estados emocionais, subjetividades, memórias, criando a sua poética particular." (LOPES, 2010, p. 135)

Para o sociólogo canadense Erving Goffman, o termo performance está intimamente ligado as nossas ações banais e do cotidiano, ações desempenhadas pelo denominado ator social, o qual escolhe seu contexto de atuação, sua vestimenta e seu comportamento para se adequar a uma determinada situação e desempenhar um papel social ou uma performance social.

\begin{abstract}
A sociedade estabelece os meios de categorizar as pessoas e o total de atributos considerados como comuns e naturais para os membros de cada uma dessas categorias: Os ambientes sociais estabelecem as categorias de pessoas que têm probabilidade de serem neles encontradas. As rotinas de relação social em ambientes estabelecidos nos permitem um relacionamento com "outras pessoas" previstas sem atenção ou reflexão particular. Então, quando um estranho nos é apresentado, os primeiros aspectos nos permitem prever a sua categoria e os seus atributos, a sua "identidade social". (GOFFMAN, 2004, p.2)
\end{abstract}

Na citação acima, Goffman traz um breve apontamento sobre as construções de identidades sociais, isto é, uma construção identitária que visa tornar o indivíduo um objeto comum e reconhecível no cotidiano social. Por exemplo, quando o autor faz referência a ambientes sociais, ele discorre sobre um lugar possível em que se sabe onde encontrar pessoas específicas e que irão desempenhar um papel ou uma performance do cotidiano que seja conveniente com nossas expectativas. Pode-se pensar nos hospitais e seus funcionários ou mesmo em um bar onde. 
Desses locais espera-se encontrar indivíduos compatíveis com tais escolhas, ou seja, indivíduos sociais ou performers sociais.

Existe a concepção da performance antropológica, abordada pela pesquisadora e fundadora do Instituto Hemisférico de Performance e Política Diane Taylor, em entrevista concedida em 2002 ao projeto interdisciplinar e digital Scalar :

\begin{abstract}
Euacho muito difícil definir os estudos da performance, porque eles são claramente formados por várias disciplinas e diferentes modos de pensar sobre comportamento corporal. Temos a antropologia, temos a sociologia, temos a fenomenologia, temos a escola francesa, de [Jean-François] Lyotard em diante, tratando da performance. Por isso eu acho difícil definir se é somente um objeto de análise, se é uma praxe, se é uma episteme, um meio de conhecimento, se é uma transação comercial, se é uma medida de eficácia. O que importa para mim em relação à performance, e aos estudos da performance, é que ela nos permite olhar para todas essas coisas como se constituindo mutuamente, de maneira que não dá para pensar sobre comportamento e práticas corporais sem pensar sobre performances disciplinares - como construímos gênero, como construímos raça, e como somos construídos como corpos - mas ao mesmo tempo há um aspecto verdadeira e maravilhosamente libertador e contestatório, porque podemos performar de maneiras diferentes; a performance refere-se a uma ação, a uma intervenção, a uma quebra estrutural e a uma busca de novas alternativas. Por isso eu acredito que os estudos da performance não são uma coisa específica, e que a sua polivalência é, na realidade, o que há de mais promissor nesse campo.
\end{abstract}

A amplitude da discussão do termo performance também é debate no grupo brasileiro pioneiro de estudos em Antropologia da Performance, o Napedra. Coordenado pelo professor e pesquisador John C. Dawsey, os debates ligados a performance ocorrem através da aproximação entre Antropologia e Teatro, visto que os teóricos fundamentais para o grupo são Victor Turner, antropólogo britânico, e Richard Schechner, diretor americano de teatro. Para a Antropologia da Performance, ainda é possível realizar seu estudo e análise a partir da Linguística. Tais apontamentos reiteram o caráter interdisciplinar ligado ao termo performance, independente da área fenomenológica em que ela é analisada e ampliam seu campo de conhecimento e debate no Brasil.

Para Richard Schechner, teórico influente sobre as pesquisas do grupo Napedra
Em grupos acadêmicos e artísticos, o conceito de performance adquire formas variadas, cambiantes e híbridas; há algo de não resolvido neste conceito, que resiste às tentativas de definições conclusivas ou delimitações disciplinares. Aquém ou além de uma disciplina, ou até mesmo de um campo interdisciplinar, os estudos de performance configuram para alguns autores uma espécie de antidisciplina. A partir de diferentes campos do saber e expressão artística - desde o teatro e as artes performativas à antropologia, sociologia, psicanálise, linguística, pesquisas sobre folclore e estudos de gênero - formula-se o conceito performance.

Um ponto interessante trazido pelo autor brasileiro JoséMário Peixoto Santos se trata da contextualização do surgimento da linguagem da arte da performance nos anos 1970. A isto, ele se refere:

Nesse contexto artístico-histórico, surgiram os movimentos hippie; feminista; gay; estudantil; também a luta pelos direitos civis dos negros e contra o preconceito racial; a valorização de atitudes ecológicas e espiritualistas (Woodstock; Literatura Beatnick; Stonewall Inn; Maio de 1968 na França; os Black Panters em legítima defesa; a chegada de mestres espirituais da Índia ao Ocidente a exemplo dos yogis Acharya Rajneesh, Osho, e A.C. Bhaktivedanta Swami Srila Prabhupada, fundador do Movimento Hare Krishna), além de outras reivindicações relacionadas aos direitos humanos na contemporaneidade - movimento mais abrangentemente conhecido como contracultura.

Em campos acadêmicos e artísticos, o conceito de performance adquire formas variadas, cambiantes e híbridas. Há algo de não resolvido neste conceito que resiste às tentativas de definições conclusivas ou delimitações disciplinares. (...) A partir de diferentes campos do saber e expressões artísticas - desde o teatro e as artes performativas à Antropologia, Sociologia, Psicanálise, Lingüística, pesquisas sobre folclore, e estudos de gênero - formula-se o conceito de performance. (DAWSEY, s/p, 2010.)

Pode-se concluir que todos os termos criados para se referir a performance são termos cunhados historicamente a fim de se refletir sobre o próprio desenvolvimento da prática performática. Visto que é uma linguagem recente, estes termos servem de caminhos e direções, tanto para artistas quanto para críticos teóricos, sobre o que esteve e está sendo produzido no campo da arte ao vivo. As delimitações dos termos estão menos associados a demarcar o que é performance do que a reconhecer o que é o processo de performance, pois o processo é muito mais amplo e muitas vezes não condiz com um termo fechado em si mesmo, mas com aspectos de diferentes termos. Por exemplo, 18 Happenings In 6 Parts, como já mencionado, é tido como um 
evento de ações fortuitas, não programadas e espontâneas, características do happening. Porém ao se estudar sobre este acontecimento, sabese que houve ensaios antes da apresentação e que no decorrer dela todas as ações do público eram guiadas pelo artista propositor da ação, sendo assim destituída a noção de que o público participava espontaneamente. Para alguns críticos, a performance é tida como uma ação mais elaborada em relação ao happening, a qual contém um script, por exemplo. Na ação de Alan Kaprow, vê-se que o maior happening reconhecido pela história da arte na verdade tem características tanto do happening, como conceito bem definido, como da performance, e é por isso que não é possível encaixar as ações performáticas em termos delimitados, e talvez por isso exista tantos termos, pois com a necessidade de se delimitar o que é performance também se tem a necessidade de delimitar o que é parecido com ela.

O corpo é veiculo de comunicação no cotidiano, em nossas relações com o mundo. A pesquisadora brasileira Christine Greiner reitera a importância do corpo como motor de relações expressivas:

o próprio corpo resulta de contínuas negociações de informações com o ambiente e carrega esse seu modo de existir para outras instâncias de seu funcionamento. Cada tipo de aprendizado traz ao corpo uma rede particular de conexões. Quando se aprende um movimento, aprende-se junto o que vem antes e o que vem depois dele. Nesse aspecto, vê-se instalada no corpo a própria condição de estar vivo e ela se apoia basicamente no sucesso da transferência permanente de informação. (GREINER, 2011).

Talvez o fato de que nossos movimentos corporais estejam estritamente associados a um tipo de comunicação funcional, a qual por vezes se torna uma ferramenta de alienação para uma compreensão mais profunda do outro, ler uma performance pode ser uma tarefa complexa para qualquer espectador, pois a quebra de sintaxe que corresponde a um gesto e seu significado cotidiano é rompido e portanto incompreendido quando fora de contexto. O autor argentino Jorge Glusberg descreve que na performance

Os programas comportamentais e gestuais não vão responder, exceto em certos casos, às convenções comuns, e sim, ao invés disso, impor novos significados, totalizando uniões de campos semânticos, dinâmicos e flexíveis. A essência, e acreditamos que isso seja fundamental, é que a body art e a performance não trabalham com o corpo, mas com o discurso do corpo. Porém a codificação a que está submetido o discurso é oposta as convenções tradicionais; embora parta das linguagens tradicionais ela acaba por entrar em conflito com elas. (GLUSBER, 2007, p.56-57)

Isso faz com que o espectador não consiga dispor de um pressuposto conotativo das ações executadas pelo performer com as ações que ele reconhece funcionalmente no mundo, ou seja, não é possível conceber a performance com a facilidade com a qual se concebe os atos cotidianos. Há uma naturalização do corpo como veiculo funcional, desprovido de significado e expressividades comunicantes. $\mathrm{Na}$ performance o corpo funcional é transgredido e o público se depara com a tentativa de conceber a ação de forma racional, o que na realidade pode ser impossível, visto que a ressignificação pressupõe novas formas de pensar o corpo.

Acredito que a relevância do discurso do corpo está justamente na quebra de significado/ significante e na sequente incompreensão do ato, pois em um mundo onde a certeza detentora de conhecimentos é preponderante, o espaço para uma inteligência imaginativa não é instigado e não se desenvolve, trazendo preconceitos em relação à arte da performance. A crítica de arte mexicana Avelina Lesper redigiu um texto chamado Contra el Performance, no qual ela visa menosprezar a performance como meio e discurso.

La gran inspiración de muchas de estas acciones son los programas de concurso y los reality-shows en los que someten a pruebas absurdas y degradantes a los concursantes, quienes por pobreza o sed de fama se humillan para ganarse un premio. (...) Un movimiento que surgió como rompimiento, y que no requería de comprensión, ha degenerado en obras que acumulan explicaciones y discursos alineados con el statu quo. Ninguna de estas manifestaciones demuestra talento, técnica, lenguaje o capacidad creadora.

O discurso de Avelina Lesper é claramente moderno quando ela tenta descreditar a performance como prática artística. A autora desconsidera a pluralidade de artistas performáticos existentes na atualidade e no passado e suas pesquisas artísticas, reduzindo toda performance a uma pesquisa sobre reality show. Talento e técnica remetem a execução de uma pintura renascentista e não só ela é arte. Tomo a liberdade de narrar este trecho em primeira pessoa, por ser pesquisadora e artista visual com produção em performance, para exemplificar uma visão oposta. Para mim, a performance é feita com trabalho e reflexão, e o talento para preconcebê- 
la não se ajusta a esse debate, pois ele se faz com trabalho, ele é consequência, apesar de ser um termo muito romântico e que pressupõe o mito do artista como gênio. O repúdio dessa crítica mexicana contra a performance se dá pela comentada complexidade de leitura de imagem em performance e por ela ser uma manifestação da pós-modernidade, a qual Avelina é resistente em compreender. Seu discurso se estagna na reiteração de seu gosto pessoal e purista, o que não é um problema, mas apenas um fato explanado.

A americana Peggy Phelan defende que a partir do momento em que uma performance é registrada ela perde seu caráter qualitativo que a coloca nessa categoria, e é com a seguinte passagem que Peggy inicia o livro A Ontologia da Performance:

\section{A única vida da performance dá-se no presente. A performance não pode ser guardada, registada, documentada ou participar de qualquer outro modo na circulação de representações de representações; no exato momento em que o fia, ela toma-se imediatamente numa coisa diferente da performance. E na medida em que a performance tenta entrar na economia da reprodução que ela trai e diminui a promessa da sua própria ontologia. O ser da performance, tal como a ontologia da subjetividade que aqui é proposta, atinge- -se por via da desaparição.(PHELAN, 1997, p171)}

Felizmente ou não, a documentação de performance, desde a década de 1960 e iniciada por artistas, como exemplo o acervo da Franklin Furnace , de Martha Wilson, é de extrema importância para se conhecer e analisar obras que não são mais possíveis de se presenciarem ao vivo por seu caráter efêmero. Esses documentos de registros serviam e ainda servem de apoio material e reflexivo aos artistas e para o desenvolvimento de sua poética. Porém, quando a autora Peggy Phelan infere que a performance quando registrada por qualquer meio perde seu caráter qualitativo de performance, pode-se subentender que performances que sejam executadas para vídeo ou fotografia na verdade não são performances, pois o registro como escolha consciente de apresentação do trabalho é inferior a ação ao vivo. Mas e como fica a intensão do artista em relação à apresentação do próprio trabalho? A sugestão de Peggy Phelan é cabível quando se pensa, por exemplo, em um registro não intencional de performance, ou seja, um registro de qualquer pessoa do público ou instituição. Talvez a passagem de Peggy seja uma forma não intencional de tornar o performer um ingênuo em relação às imagens que são produzidas por suas ações.
Uma vídeo-performance ou foto-performance não deve ser equiparada a uma performance ao vivo se para compará-las qualitativamente, pois o tempo do vídeo e da performance ao vivo, por exemplo, são diferentes. A performance no vídeo existe independente de ser acionado, é um tempo resguardado. Tem-se a ação performática a qualquer momento em que se executar o vídeo, e a qualidade da apresentação, nesse caso, está ligada ao display, isto é, ao tamanho, formato e tipo de aparato que irá se exibir tal vídeo, visto que hoje temos projeções que alcançam dimensões exorbitantes e sem perder a qualidade da imagem, bem como televisores cada vez maiores e mais tecnológicos. Assistir a uma vídeo-performance no Youtube e na tela padrão do computador não é tão interessante visualmente quanto assisti-la em uma tela de projeção com tamanho e qualidade que não estejamos habituados em nossa casa. Porém a ação performática no vídeo, independente do display, continua a mesma e sem alteração no tempo e espaço interno da imagem do vídeo.

Quando Peggy Phelan discorre sobre "desaparição" em performance, ela está se referindo justamente a falta de possibilidade de um novo acesso e repetição dessa ação, pois a repetição é vista como uma característica e estratégia de mercado, logo negativamente. Porém, tem-se sempre que levar em consideração a intencionalidade do artista ao escolher apresentar por diferentes meios a materialização de seu processo criativo.

O artista desenvolve a performance, a qual se pode tomar como um produto de arte, porém efêmero, se considerada como arte ao vivo devido à sua duração e materialização da presença se dar em um período pré-estabelecido, curto ou longo, mas que jamais será o mesmo de uma obra de arte convencional que perdura por anos como um mesmo objeto e por vezes num determinado local. Talvez não seja necessário atribuir a performance apenas o tempo presente como um elemento estético e de fator decisivo, mas apenas ter consciência da utilização do tempo vídeo e do tempo presente.

Lucio Agra, pesquisador brasileiro é um grande fomentador da discussão da performance em São Paulo e no Brasil nos últimos anos. Junto a demais pesquisadores, ele organiza a Associação Brasil Performance, a fim de mapear os festivais e eventos realizados no país, assim como fóruns 
de debates permanentes. Para Agra, o Brasil é referência em produção e pioneirismo sobre o assunto na América Latina, visto que as datas das experiências do artista Flávio de Carvalho não têm precedentes nessa grande região.

Agra sugere que a performance seja uma "perfeita tradução do contemporâneo" (AGRA, 2011, p. 16) e isso remete às discussões travadas sobre o conceito de pós-modernidade a partir de autores como o francês Jean François Lyotard e o americano Frederic Jameson, discorrendo sobre algo que desencadeia na percepção da constante atualização do presente na pós-modernidade: a perda da noção de história linear, e logo de um passado concreto calcado por grandes narrativas, reiterada pelo acesso a hiperlinks, pelos quais o presente é constituído de informações passageiras, líquidas , trazendo a efemeridade do tempo/duração contida na performance como elemento estético como possível forma fenomênica e singular da pós-modernidade e a imprevisibilidade contida em tais atualizações do presente. Por isso, para concluir este capítulo, utilizo do parágrafo de conclusão de Agra em sua publicação na Revista de Pós-graduação da UnB, 2012:

Se ainda assim se quiser outras razões, resumo as expostas aqui: o caráter de expansão da linguagem, sobretudo atualmente; a sua "natural" resistência à apreensão cognitiva racionalista, a sua amplificação geográfica, a sua reverberação em vários contextos (ela mesma sendo um), sua congenialidade a outras formas emergentes de invenção artística que resultam de misturas e apropriações de formas tradicionais ou sucatas culturais, a sua predileção pelo evento efêmero, precário, dificilmente apreensível, a sua resistência às clássicas ordens identitárias, o seu caráter de proximidade ao subalterno, sua expansão em lugares antes ignotos, sua formulação em uma temporalidade espiralada (sem a teleológica perspectiva de um progresso linear-ascendente), a amplitude de seu campo de pesquisa, sua ilógica, sua predileção pelo paradoxo, o experimental. Por que deveríamos abrir mão desta conquista que é dispormos de um modo de dizer/fazer/pensar em arte que resiste às definições? Vamos adiante afirmando a dúvida.

É interessante notar como estudiosos da performance reconhecem a dificuldade em delimitá-la, isto é, torná-la um conceito fechado em si mesmo, pois talvez delimitar o seu significado esteja relacionado a uma falta de compreensão da amplitude e hibridez que há em sua teoria e prática. Talvez não se trate de analisar o termo como um designativo geral e panorâmico de uma prática, mas as práticas pelas quais se constitui a performance.

\section{NOTAS}

1. Intermídia é um termo criado pelo fundador do FLUXUS, George Maciunas, para designar a integração e hibridização entre diferentes linguagens ligadas a arte e a cultura em uma mesma manifestação artística.

2. O Grupo Rex foi fundado pelos artistas Wesley Duke Lee, Geraldo de Barros e Nelson Leirner. 0 intuito do grupo era fazer experimentações com diversas linguagens, atualizando o cenário brasileiro ao realizarem controversas obras de arte e exposições ligadas ao happening internacional. As atividades do grupo são muitas vezes comparadas as atividades do FLUXUS.

3. Teatro da Crueldade é uma teoria teatral proposta por Antonin Artaud, como uma crítica à espetacularização, racionalização e à sociedade ocidental. Era preciso, pois um novo teatro e um novo espectador para romper paradigmas e para isso ele calcou a estruturação de tal proposta na condição pré-verbal e na psique humana.

4. A Franklin Furnace funciona até os dias de hoje, e seu papel fundamentou consistiu na catalogação, documentação, promoção e preservação de artes efêmeras, como livros de artistas, instalações, vídeos e performances ao vivo ou online.

5. O Instituto Hemisférico de Performance e Política, criado em 1998, é uma rede multilíngue e interdisciplinar de instituições, artistas, acadêmicos e ativistas políticos de todas as partes das Américas que trabalha na interseção entre a academia, expressão artística e a política. A organização explora as práticas do corpo - a performance - como veículo para a criação de novos significados e a transmissão de valores culturais, de memória e de identidade. Fonte: http://hemisphericinstitute.org/hemi/pt

6. O projeto Scalar faz a mesma pergunta a trinta acadêmicos de diferentes países das Américas: 0 que são estudos de performance?

Fonte: http://scalar.usc.edu/nehvectors/wips/ diana-taylor-portuguese

7. Núcleo de Antropologia, Performance e Drama Universidade de São Paulo, Brasil.

8. DAWSEY; John C. MÜLLER, Regina; HIKIJI, Rose S. G; MONTEIRO, Marianna F. M. Antropologia e Performance: Ensaios Napedra. São Paulo: Terceiro Nome, 2013, p18. 
9. A Franklin Furnace funciona até os dias de hoje, e seu papel fundamentou consistiu na catalogação, documentação, promoção e preservação de artes efêmeras, como livros de artistas, instalações, vídeos e performances ao vivo ou online.

10. MEDEIROS, Maria Beatriz de. Corpos informáticos: arte, corpo, tecnologia. Brasília, DF: FAC: UnB, 2006.

11. "A Associação nasce em 2010, com a necessidade de dialogar com o meio cultural e artístico brasileiro e internacional, a fim de pensar e reivindicar incentivos duradouros para a performance no Brasil. Uma das tarefas da BrP, é o mapeamento da performance em São Paulo e no Brasil, necessidade evidenciada a partir das discussões dos Fóruns nas quais sempre se repetia a pergunta: quem somos? A BrP é uma associação sem fins lucrativos, aberta a todos, interessados, artistas e estudiosos da performance." Fonte: http://brasilperformance. blogspot.com.br/

12. "Zygmunt Buman é um grande pensador polonês, e o qual qualificou tão bem o célebre conceito de liquidez. Perspicaz analista dos fatos cotidianos, o sociólogo tem vasta obra sobre temas contemporâneos, com destaque para o best-seller Amor líquido, fundamental para a compreensão das relações afetivas no mundo atual." Fonte: www. zahar.com.br.

\section{REFERÊNCIAS BIBLIOGRÁFICAS}

BORBA, Jenny Granado Rocha. Publicação de Artista e Performance: Intersecções Entre Visibilidade e Valor da Aparência, Revista DAPesquisa, v.9, n.12, p 01 - 14, dezembro 2014.

COHEN, Renato. Performance como linguagem. São Paulo: Perspectiva, 2002.

DAWSEY; John C. MÜLLER, Regina; HIKIJI, Rose S. G; MONTEIRO, Marianna F. M. Antropologia e Performance: Ensaios Napedra. São Paulo: Terceiro Nome, 2013.

DAWSEY, J. C. NAPEDRA - Núcleo de Antropologia, performance e drama: em busca do lugar sentido das coisas. IN: Proa - Revista de Antropologia e Arte [online]. Ano 02, vol.01, n. 02, nov. 2010. Disponível em: < http://www.ifch.unicamp.br/proa/Relatos\%20e\%20 Experienciasll/john.html. > Acesso em Maio 2016.
DEMPSY, Amy. Estilos, Escolas e Movimentos: Guia Enciclopédico da Arte Moderna. São Paulo: Cosac Naify, 2003.

GLUSBerg, Jorge. A Arte da Performance. São Paulo: Perspectiva, 2007.

GOLDBERG, Roselee. A Arte da Performance: Do Futurismo ao Presente. São Paulo: Martins Fontes, 2006.

GOFFMAN, Erving. Estigma: Notas sobre a manipulação da identidade deteriorada. Rio de Janeiro: Guanabara, 1991.

JAMESON, Fredric. Pós-modernismo: a logica cultural do capitalismo tardio. 2. ed. - Sao Paulo: Ática, 1997.

KEIDAN, Lois. Live Art. O que é Live Art? Disponível em:

< http://www.forumpermanente.org/revista/ edicao-0/textos/liveart > Acesso em: Maio, 2016.

LIPPARD, Lucy. Seis años: la desmaterialización del objeto artístico de 1966 a 1972. Madrid : Akal, 2004.

LYOTARD, Jean-François. A condição pósmoderna. 11. ed. Rio de Janeiro: J. Olympio, 2009.

MEDEIROS, Maria Beatriz de. Corpos informáticos: arte, corpo, tecnologia. Brasília, DF: FAC: UnB, 2006.

LOPES, Beth. A performance da memória. Revista Sala Preta, São Paulo, v.9, p. 135 a 145, 2009.

SANTOS, José Mario Peixoto. BREVE HISTÓRICO DA "PERFORMANCE ART" NO BRASIL E NO MUNDO. Revista Ohun, Bahia, n) 4, p.1-32, dez 2008.

TAYLOR, Diane. 0 que são estudos de performance? Disponível em:

< http://scalar.usc.edu/nehvectors/wips/dianataylor-portuguese > Acesso em: Abril, 2016. 


\section{SOBRE O AUTOR}

Natalie Mirêdia (artístico) é bacharel em Artes Plásticas pela Universidade Federal do Espírito Santo, UFES. Possui pesquisa de Iniciação Científica pelo CNPq na área de Teoria e História da Arte Moderna e Contemporânea e Performance Artística. Desenvolve trabalhos artísticos com performances, fotografias, vídeos e objetos a partir de sua pesquisa artística Qual o resultado da equação elementos delicados x agressivos? 2014. Já participou de mostras no Brasil e no exterior, como $2^{\circ}$ Caixa Bienal de Novos Artistas (Caixas Culturais) e Venice Experimental Video and Performance Art Festival, no Palazzo Ca Zanardi, Veneza. 